REVISTA ANDALUZA DE ANTROPOLOGÍA.

NÚMERO 3: MIGRACIONES EN LA GLOBALIZACIÓN.

SEPTIEMBRE DE 2012

ISSN 2174-6796

[pp. 94-124]

http://dx.doi.org/10.12795/RAA.2012.i03.06

Fecha de recepción: 03/02/2012

Fecha de aceptación: 16/07/2012

\title{
MUJERES MIGRANTES EN LA ERA DE LA GLOBALIZACIÓN. ECUATORIANAS Y SENEGALESAS EN SEVILLA
}

EMMA MARTÍN DÍAZ

SUSANA MORENO MAESTRO

FRANCISCO JOSÉ CUBEROS GALLARDO

SIMONE CASTELLANI

GEISA. Universidad de Sevilla

\section{Resumen.}

En este artículo nos centraremos en el análisis de los datos de investigaciones diferentes, aunque conectadas entre si, llevadas a cabo por miembros del Grupo de Investigación para el Estudio de las Identidades Socioculturales en Andalucía (GEISA) sobre las mujeres inmigrantes latinoamericanas y africanas en la ciudad de Sevilla.

El objetivo principal es presentar las causas subyacentes a las migraciones de las mujeres, que están en la base de las estrategias migratorias transnacionales desarrolladas por ellas. Estas estrategias han ido evolucionando a medida que se iba conformando el proceso de integración en la sociedad de destino. En este apartado daremos un énfasis especial al proceso de inserción laboral, que, junto a las causas desencadenantes de la emigración, condicionan y modulan la integración de las mujeres. 
Vinculado con este análisis, presentaremos las dinámicas asociativas que se han ido generando en relación a las necesidades de integración social y de reproducción cultural en destino. En este apartado intentaremos demostrar cómo el protagonismo de las mujeres en las asociaciones de inmigrantes está condicionado por la propia dinámica de género de estos flujos migratorios y por los mecanismos de inserción implementados por la sociedad receptora.

Por último, avanzaremos algunas consideraciones sobre el rol de las jóvenes hijas de inmigrantes latinoamericanas en la reproducción de la identidad de género, y su repercusión en el proceso de inserción social, en un contexto en el que existe una hipervisibilidad de los varones, identificados con las bandas latinas.

Palabras clave: Mujeres, estrategias migratorias, inserción sociolaboral, asociacionismo, Ecuador, Senegal.

\section{Abstract.}

This article will focus on the analysis of the data recollected in different but interconnected researches carried out by some members of the Research Group for the Study of Sociocultural Identities in Andalusia (GEISA) with Latin American and African migrant women in Seville.

The main aim of this paper is to present the underlying causes of women's migration, which are in the basis of their migratory strategies developed both in origin and destination. These strategies have been evolving in parallel with the integration process into the host society. A particular emphasis will be given to the integration into the labour market, which, along with the triggering causes of migration, condition and modulate the process of integration of these women.

Linked with this analysis, the association dynamics which have grown in connection to the needs of social and cultural reproduction in the host society will be explained. This section will try to confirm how the prominent role of women in immigrant associations is conditioned by the gender dynamics of these migratory flows as well as by mechanisms for integration implemented by the host society.

At last, some considerations about the role of Latin American migrants' daughters in the reproduction of gender identity and its impact on the social integration process will be pointed up, taking into account a context where a strong visibility is given to the boys as members of Latino's gangs.

Keywords: Women, migratory strategies, social and work integration, associationism, Ecuador, Senegal. 


\section{LAS MIGRACIONES FEMENINAS}

Las migraciones masivas han seguido unas pautas diferenciadasen relación ala pertenencia del sujeto a los diferentes sistemas de sexo/género, los cuales, a su vez, están en relación con las distintas culturas étnicas y nacionales presentes en los distintos Estados-nación. Como hemos venido afirmando a lo largo de nuestras publicaciones (Martín y Sabuco, 2006), hombres y mujeres desarrollan diferentes estrategias tanto para la emigración como para la inserción social en los países de inmigración. Esta diferencia es claramente perceptible tanto en las políticas de inmigración como en las representaciones sociales que se originan sobre los procesos migratorios. Como señala Sassen (2003: 46), "las dinámicas de género han sido invisibilizadas en términos de su articulación concreta con la economía global. Este conjunto de dinámicas puede encontrarse en los circuitos alternativos transfronterizos..., en los cuales el rol de las mujeres, y especialmente la condición de mujer migrante, es crucial". En este sentido, las migraciones transnacionales aparecen como un lugar privilegiado para estudiar la transformación de los patrones de género. En este sentido, el estudio de la formación de las unidades domésticas transnacionales arroja datos esclarecedores sobre el empoderamiento de las mujeres, permitiendo la validación de determinadas hipótesis formuladas al respecto por la corriente feminista de la literatura sobre la globalización. Permiten observar la creación de nuevas formas de solidaridad transfronterizas, y las experiencias de pertenencia y de elaboración de identidad que representan las nuevas subjetividades femeninas. Volviendo a Sassen (2003: 50) "mujeres e inmigrantes emergen como el equivalente sistemático del proletariado, un proletariado que se desarrolla fuera de los países de origen. Además, y por otra parte, las demandas de la fuerza de trabajo del máximo nivel profesional y gerencial, en las ciudades globales, son tales, que los modos corrientes de manejar las tareas y los estilos de vida domésticos se vuelven inadecuados. Como consecuencia estamos observando el retorno de las llamadas "clases de servidumbre" compuestas en su mayoría por inmigrantes y mujeres inmigrantes". Una contribución empírica a este enfoque puede encontrarse en Martín y Sabuco (2006).

Es ya un lugar común que la globalización económica ha supuesto una feminización de la pobreza y, consiguientemente, un incremento de las migraciones femeninas. Sin embargo, son menos conocidos los efectos de esta situación sobre las sociedades en general y sobre las mujeres en particular. Las migraciones femeninas no son un fenómeno nuevo, lo que ha tenido lugar es un incremento de las mismas y, sobre todo, un mayor interés por su estudio. En la actualidad, en lugares como Europa y América del Norte, las mujeres representan más del $50 \%$ del total de la inmigración a estos países. Pero esta no es ni la única ni la principal novedad. El hecho más significativo es el incremento del número de mujeres que emigran siguiendo un proyecto autónomo que las convierte en las principales proveedoras y cabezas de hogar. 
La renovada importancia de las mujeres en el contexto de las migraciones de la globalización ha llamado la atención de numerosos investigadores del tema. Puede afirmarse, si bien con matices, que la variable género ha pasado a ser incorporada como central por buena parte de los estudiosos. Una tendencia especialmente apreciable en los trabajos que han abordado la reciente migración ecuatoriana a Europa, debido precisamente al protagonismo que las mujeres han ostentado en ellas. En este sentido, se debe subrayar los resultados obtenidos de incorporar el género como variable central. Especialmente a la hora de analizar temáticas como las redes de inserción sociolaboral (Actis, 2005), la organización del cuidado (Herrera, 2005), las transformaciones en los modelos familiares (Pedone, 2005) o la gestión de las remesas (Martín et al., 2008).

Como venimos afirmando, la perspectiva de género ha cobrado significación en los análisis de los procesos migratorios desde hace sólo unas dos décadas. Por un lado, el enfoque transnacionalista (Basch, Schiller y Szanton Blanc, 1994) y por el otro, los estudios que han analizado la feminización de la migración en la era de la globalización (Sassen, 2003) han puesto de manifiesto cómo el papel de la mujeres ya no puede quedar oculto bajo el presupuesto de sentido común que la migración es una estrategia emprendida por varones para cumplir con el rol de producción que mantienen en el grupo domestico. Aunque las mujeres en las investigaciones recientes empiezan a emerger como protagonistas de los procesos migratorios, hay otros actores que participan en ellos y que siguen quedando en la sombra: los menores de edad, hijas e hijos de las y los migrantes.

Ninguno de los actores implicados en la gestión del proceso de integración ha sido ajeno a la característica feminización de esta corriente migratoria. Tanto la Administración pública como los representantes del Tercer Sector y del sector privado se han apresurado a incorporar el género como eje prioritario en sus prácticas y discursos. Todos ellos parecen coincidir en la necesidad de adaptar sus iniciativas para reconocer y aprovechar el papel protagonista de las mujeres en la migración a Europa. Si bien cabe distinguir importantes diferencias en los modelos de mujer que unos y otros manejan en sus discursos, son recurrentes en todos ellos las alusiones a la especial vulnerabilidad que se supone a las mujeres; y paralelamente, a su pretendida capacidad para suavizar y favorecer el contacto intercultural. La consecuencia práctica de este consenso es una apuesta por la visibilización de la identidad de género en las políticas públicas e iniciativas sectoriales enfocadas a la integración social de los inmigrantes, que en muchas ocasiones tienen lugar sin un adecuado conocimiento de la realidad social que está en la base de las estrategias y discursos de las mujeres migrantes.

\section{LAS MUJERES ECUATORIANAS: LA CRISIS COMO CATALIZADOR}

Las mujeres ecuatorianas vienen a España a trabajar, y consecuentemente viajan en edades adecuadas a este requisito. Son muy pocas las que definen su extracción socioeconómica como "muy humilde o pobre", mientras que la mayor parte se identifica como procedente 
de una situación "modesta pero suficiente" e incluso "acomodada". Encontramos aquí la primera diferencia significativa entre la lectura que estas mujeres hacen de su propia situación y otras que suelen ser difundidas desde el exterior y que las catalogan como víctimas de situaciones de pobreza severa (Floro, 2001; UNFPA, 2002). Entendemos que este diferente punto de partida debe ser tenido en cuenta a la hora de analizar los discursos y estrategias de estas personas, sobre todo por cuanto implica rasgos específicos en el modo de afrontar la inserción en los mercados laborales en España y en Andalucía y en el seno de las sociedades de destino. Son muchas las mujeres que citan expresamente haber sentido un doloroso descenso en su posición de clase en su proceso de inserción en la sociedad de destino (Herrera, 2003; Martín et al., 2008).

Uno de los aspectos más relevantes es el referente al motivo de la empresa migratoria. En el discurso de estas mujeres, causas de diversa naturaleza convergen y se imbrican, llegando a ser difícil a menudo discernir el peso de cada una. Una gran parte citó como causa principal de su migración factores relativos a la crisis político-económica que afectó al país a fines de los noventa. De hecho la crisis está presente, de modo explícito o latente, en el discurso de casi todas ellas. Algo coherente por otra parte con la extendida interpretación que enfatiza la importancia de los factores macro como causa de las corrientes migratorias. Sin embargo, y sin negar la considerable importancia de tales factores, los datos recabados nos obligan a matizarla. Fueron más aún las mujeres que citaron, como motivo principal de su decisión de migrar, el tener a su disposición redes que facilitaban esta opción. Se introduce de este modo en el análisis una variable cuya trascendencia resulta a menudo subestimada: la dinámica de las propias redes transnacionales como estructuras que fortalecen el flujo migratorio, por cuanto abaratan los costes de la estrategia migratoria (Ramírez y Ramírez, 2005; Herrera, 2004).

En el discurso de estas mujeres, tanto la crisis ecuatoriana como la disposición de redes facilitadoras son factores que suelen aparecer entrelazados a la hora de identificar las motivaciones. Sin embargo, conviene tener en cuenta qué otros factores pueden quedar ocultos en tales discursos, por ser considerados íntimos o bien por no encajar en el modelo de respuesta correcta que el entrevistado puede creer adecuado a la situación de entrevista. Hay situaciones que son más fácilmente "confesables" que otras. Con frecuencia, el impacto de la crisis económica que estas mujeres refieren de modo explícito al ser preguntadas se matiza a lo largo de la observación-participación, arrojando nuevos datos relativos a cuestiones de género. La crisis se concreta a veces en mujeres abandonadas por sus parejas, o en precarios modos de equilibrio económico amenazados por varones de la familia. Debe notarse que hasta cinco de las mujeres entrevistadas citaron expresamente, como causa principal de su decisión de emigrar, problemas con sus parejas o sus familias relacionados con desigualdades de género. Así que, en términos generales, podemos decir que la migración, más que el efecto mecánico de una crisis estructural, resulta una 
estrategia factible que es aprovechada por las mujeres ecuatorianas, las cuales incluyen estrategias generizadas en la planificación y desarrollo de sus estrategias como migrantes (Herrera, 2004; Martín, 2008; Cuberos, 2008; Goicoechea y Ramírez, 2002).

La contracción temporal de la migración ecuatoriana produce unos patrones homogéneos en el diseño e implementación de las estrategias de tránsito y de inserción social (Pujadas y Massal, 2002). La llegada masiva de ecuatorianos tiene lugar en un periodo corto, y la posibilidad de entrar como turista determina un modelo claramente diferenciado. En un primer momento, para entrar en España se necesitaba un visado de turista, lo que implicaba estar en posesión de una serie de requisitos: billete de ida y vuelta, bono de hotel y una bolsa de viaje que acreditara la condición de turista del inmigrante. Numerosas agencias de viaje en Ecuador se especializan, a partir de 1999, en el tránsito de los nacionales del país que quieren emigrar a España, proporcionándoles no sólo el pasaje de avión y el alojamiento, sino también la información necesaria para pasar la aduana sin levantar sospechas. La exigencia de visado supuso la quiebra de muchas de estas agencias, que habían surgido como consecuencia de la migración masiva (Martín et alii, 2008).

La mayor parte de las mujeres ecuatorianas encontraron trabajo a los pocos días de llegar, si es que no lo tenían ya desde antes de partir. En este primer empleo son esenciales las mujeres que llegaron primero, generándose una red femenina de carácter informal que presenta un alto grado de eficacia para la inserción laboral de estas recién llegadas, pero que también funciona como entidad para el reclutamiento en origen (Sassen, 2003; Herrera, 2006). Quizá lo más interesante de este proceso es que esta red en destino se articula con una red en origen que se dedica a prestar el dinero del viaje a las mujeres que quieren emigrar. De esta forma, la dimensión transnacional de la emigración queda claramente patente: no sólo permite subsistir a los emigrantes en destino y a sus familias en origen, sino que da la oportunidad de crear un nuevo nicho de actividad económica en los lugares de origen, ya que muchos de los prestamistas son familiares de personas que están en España, y que a su vez prestan este dinero a mujeres a las que su familiar les ha buscado un trabajo en este país, con lo que se cuentan con ciertas garantías previas de recuperación de la inversión. Se produce entonces un proceso de capitalización de estas redes que a su vez, otorga nuevos impulsos a la emigración (Martín et al. 2008).

Una prueba de lo que afirmamos es que la mayoría de las mujeres afirmaron haber pagado la deuda antes del año de su estancia en el país. Incluso hemos recogido testimonios de mujeres que fueron abordadas por potenciales empleadores el mismo día de su llegada a territorio español. Esta realidad contrasta con la experiencia de otros colectivos que han necesitado referencias previas para su incorporación al trabajo doméstico (Martín y Sabuco, 2007). 


\section{CAUSAS DE LA MIGRACIÓN DE LAS MUJERES SENEGALESAS}

Es necesario observar la presencia de mujeres africanas en los procesos migratorios en el contexto de la globalización, que no es solamente neoliberal sino, también, colonial y patriarcal. El colonialismo en África supuso un declive general en la posición de las mujeres en relación a los hombres, pues los funcionarios coloniales aceptaron los estereotipos de género occidentales, relegando a las mujeres al ámbito doméstico y dejando los asuntos económicos y políticos a los hombres (Parpart, 1988). Esta pérdida de poder de las mujeres se generaba, sobre todo, en relación al acceso a la tierra y la fuerza laboral. La percepción de los funcionarios era que los hombres eran los campesinos y productores de alimentos en África y, así, cuando se comercializaron los derechos a la tierra, fueron los hombres, considerados los cabezas de familia, quienes recibieron los títulos de propiedad. Se consideró a las mujeres como "simples" agricultoras de subsistencia, mientras que los hombres se identificaron como potenciales agricultores de cultivos industriales y, por lo tanto, con derecho a asistencia técnica. Esta consideración, que se perpetúa con el tiempo, continúa hasta nuestros días.

En África existen hoy datos "objetivos" de empobrecimiento: supresión de empleos en la Función Pública, bajada de las remuneraciones, crisis en la venta de materias primas, alza de los precios de alimentos básicos, aumento de los precios de productos agrícolas y medicamentos, carencias alimenticias. La mayoría de estos síntomas, que funcionan como criterio de pobreza, son el resultado del sistema económico mundial. La globalización capitalista implica el agotamiento de recursos naturales y la destrucción del medio ambiente, lleva a primar los cultivos de exportación sobre la agricultura familiar ${ }^{1}$, provoca el hundimiento de industrias artesanales, favorece la invasión de capitales y productos del Norte, y conduce a la falta de libertades públicas para el mantenimiento de regímenes políticos autoritarios que garanticen el "buen" funcionamiento del sistema. La gran expulsión de población es consecuencia directa de todo esto. Son de estas regiones del mundo excluidas de los centros de poder - entre las que está incluida África- a las que se ha asignado un papel subalterno en la división internacional del trabajo, de donde parten muchas de las personas que aspiran a mejorar sus condiciones de vida y la de sus familiares.

Particularmente, en Senegal se produjo el hundimiento de los tres sectores de la economía como consecuencia de la puesta en práctica de políticas de liberalización comercial y de privatizaciones impuestas por el Fondo Monetario Internacional y el Banco Mundial. La reestructuración de la Función Pública se tradujo en la congelación de salarios, despidos masivos y programas de "retiro voluntario" para cumplir con las

1. Los desplazamientos forzados consecuencia del acaparamiento de millones de hectáreas provocan movimientos internos mucho más significativos tanto social como numéricamente que los que se producen desde África a Europa. 
exigencias de los Planes de Ajuste Estructural; los despidos masivos de trabajadores en el sector público repercutieron, por un lado, en el trabajo de las mujeres, creciendo sus responsabilidades en los hogares para satisfacer las necesidades familiares ${ }^{2} \mathrm{y}$, por otro lado, en un crecimiento de la denominada "economía informal"3 ante la dificultad de poseer empleo y salario. Ante toda esta situación, dos realidades se ponen de manifiesto en el conjunto de mujeres senegalesas: la de una emigración masculina que les deja a ellas gran parte de las actividades agrícolas en el país de origen -además de un mayor trabajo en casa- y la de aquellas que deciden también emigrar. Por lo tanto, es erróneo aquel planteamiento que afirma que la mujer que emigra lo hace siempre para reunirse con su marido. En algunos casos sí es así pero, otras veces, la mujer entiende su emigración como estrategia para mantener su grupo doméstico como cabeza de familia, sin ir detrás de ningún hombre.

\section{LA INSERCIÓN EN EL SERVICIO DOMÉSTICO COMO PRINCIPAL NICHO LABORAL PARA LAS MUJERES ECUATORIANAS}

El servicio doméstico debe afrontar una situación de partida claramente negativa para su reconocimiento como actividad laboral. Una ocupación imprescindible para la producción y reproducción de la fuerza de trabajo, y por tanto, para la reproducción social, que, sin embargo, tiene que enfrentarse a la consideración, ampliamente generalizada, de no-trabajo. La identificación entre el hecho biológico de la reproducción y el trabajo doméstico supone la aceptación de que las mujeres están dotadas, por el simple hecho de pertenecer al sexo femenino, de una serie de saberes y habilidades que las capacitan para el desempeño de las tareas del hogar.

En el momento actual tienen lugar una serie de transformaciones en el seno de las unidades familiares que suponen un incremento de la demanda del trabajo asalariado en este sector, como son la incorporación de las mujeres a los mercados de trabajo, la recomposición de los hogares mediante el aumento de las familias reconstituidas, o el aumento de la esperanza de vida, y, consiguientemente, del número de ancianos que viven solos. Estas transformaciones inciden en el alza experimentada en el sector doméstico, y lo convierten en uno de los (escasos) yacimientos de empleo con más futuro, aunque en condiciones de precariedad y de no-reconocimiento social.

2. Como las Políticas de Ajuste Estructural no tenían como finalidad el desarrollo de los países sino la reducción de la deuda externa acabando para ello con los presupuestos dedicados a sectores "no productivos", como la salud o la educación, las mujeres se vieron obligadas a encargarse de gran parte de estos servicios debido a la concepción ideológica del género, que les reserva las tareas de reproducción y cuidado del núcleo familiar.

3. Podemos traer varias definiciones de economía informal. Así, para Castells y Portes (1989:12), la economía informal es la formada por todas aquellas actividades generadoras de ingresos que no están reguladas por el Estado en entornos sociales donde actividades similares están reguladas. Por su parte, la OIT (2002) define la economía informal como todas las actividades económicas de trabajadores y unidades económicas que no están cubiertas por las disposiciones oficiales que las encuadran. 
El incremento de la demanda no llega a ser cubierto por las trabajadoras autóctonas, en especial cuando debe paliar unas necesidades de dedicación a tiempo completo. La llegada de las mujeres inmigrantes, y la cada vez más significativa feminización de las migraciones, han venido provocando una serie de cambios en este sector, teniendo lugar un proceso de sustitución en algunos campos, particularmente en el sector de las internas. Una vez incorporadas a este mercado de trabajo, se produce una "etnificación" de la actividad, que amplia la demanda a otros sectores: las externas y las que trabajan por horas.

Las especiales características que definen el trabajo doméstico se ilustran palmariamente en la legislación que regula esta actividad. Conviene recordar aquí que, pese a que encontramos algunos hombres -autóctonos e inmigrantes- trabajando en este sector, estamos ante una actividad básicamente femenina, y que la variable de género se encuentra muy presente en el desarrollo legislativo.

La legislación del servicio doméstico es una prueba palpable de la diferencia existente entre las actividades económicas que tienen lugar en el ámbito privado y en el público, y de la consideración de que sólo es trabajo el que se desarrolla en este último. El reconocimiento del servicio doméstico como actividad laboral fue un proceso jalonado de dificultades. Sólo en 1985 se promulga el Real decreto 1.424, que aunque reconoce la relación laboral, le otorga un "carácter especial". Este carácter especial está en directa relación con el ámbito en el que tiene lugar la actividad: el hogar, que posee un estatuto jurídico especial al ser el espacio privilegiado de los derechos fundamentales relacionados con la intimidad: el derecho a la privacidad, sagrado en la tradición liberal de la modernidad. Una legislación laboral supondría otorgar una dimensión "pública" a este espacio. Por ello, en la regulación de la actividad se hace referencia a la "mutua confianza" entre las partes, al mismo tiempo que la Inspección de Trabajo sólo podrá realizarse salvaguardando el derecho a la inviolabilidad del domicilio y el respeto a la intimidad.

La creciente incorporación de las mujeres a los mercados de trabajo ha generado un importante incremento de la demanda en el servicio doméstico, particularmente en las grandes zonas urbanas. Sin embargo, sería inexacto considerar que esta incorporación laboral es el único factor determinante. Existen otros factores que conviene destacar, y entre ellos, destaca el hecho de que una parte importante de la población femenina que trabaja fuera del hogar reside fuera del lugar donde radica su familia extensa, lo que dificulta la recurrencia a las redes de parentesco en las tareas domésticas, particularmente en lo que refiere al cuidado de los niños y ancianos. Al contrario de lo que sucede en otros países de la UE, en España no existe una legislación laboral protectora de los derechos de la familia que garantice la posibilidad de simultanear los trabajos domésticos y los extradomésticos. Esta realidad genera también una mayor demanda de servicio doméstico. 
A estos factores hay que añadir los que suponen un incremento de la oferta. Es indudable que las nuevas migraciones han supuesto una importante solución a los problemas que presenta el cuidado de los hogares, hasta el punto de que en determinados lugares como Madrid o Barcelona la mayor parte de la población inmigrada en situación de alta en la Seguridad Social es básicamente una inmigración femenina y empleada en el servicio doméstico. A este hecho no es ajeno en absoluto el desarrollo de las políticas de inmigración, pero tampoco la diferencia de género que vincula y atribuye a hombres y mujeres papeles diferentes en el seno de la sociedad. Así, inmigrantes y mujeres están fuertemente sobrerrepresentados en los sectores de la economía informal. Este acceso desigual a los mercados de trabajo tiene como consecuencia la mayor dificultad de la regulación de la inmigración femenina. Si el modelo que se presenta como válido para el reconocimiento de los derechos de los inmigrantes vincula éstos con su funcionalidad económica, y la inmigración “ordenada” es la que tiene lugar como consecuencia de las necesidades económicas de la sociedad de acogida, las dificultades, preexistentes a la inmigración, para el reconocimiento del servicio doméstico como actividad laboral van a determinar los problemas específicos que tienen las trabajadoras inmigrantes en este sector.

Por otra parte, el sector del servicio doméstico ha sido tradicionalmente el mecanismo de acceso más recurrente, junto con la reagrupación familiar, a la regularización de la población femenina. El problema es que las mujeres inmigrantes, en la medida en que se incorporan al servicio doméstico, se ven sometidas a una doble limitación. Como inmigrantes, $y$, por tanto con una restricción importante de sus derechos, y como domésticas, y, por tanto, sujetas a una legislación laboral discriminatoria con respecto a otros sectores de actividad. La regularización por esta vía, lejos de ser un mecanismo que permita la superación de las situaciones de discriminación, acentúa la dependencia de las trabajadoras, en la medida en que su labor se desarrolla en el ámbito privado, y, por ello, con importantes restricciones para la vigilancia del cumplimiento de la legalidad. A ello hay que añadir que en muchas ocasiones la relación contractual cesa en cuanto se obtiene la regularización, ya que muchas mujeres prefieren darse de alta como autónomas para así poder cambiar de trabajo en busca de mejores oportunidades, aunque éstas se encuentran casi siempre dentro de este sector Martín, 2006, 2008).

Si la crisis de 1999 en Ecuador es un factor estructural en la emigración ecuatoriana hacia España (Ramírez y Ramírez, 2005), la inserción laboral en el ámbito doméstico determina las opciones de la migrante en la sociedad de destino al limitar su visibilidad como sujeto social. Ambos elementos se articulan para imponer una serie de condiciones que, por una parte, dificultan el empoderamiento de las mujeres, y, por otra, velan los logros alcanzados. En origen, la crisis económica desestructuró la economía política de los hogares de las migrantes. Muchas veces esta economía estaba basada en delicados 
equilibrios en los que la suma de esfuerzos y de voluntades de las redes de mujeres, tanto familiares como amigas y vecinas, proporcionaban los recursos, materiales y simbólicos, para la subsistencia (Herrera, 2003). La combinación de una inflación galopante con una creciente inestabilidad política inició el derrumbe de esta forma de vida, sobre la que se habían articulado los proyectos de futuro de las capas medias y bajas de la sociedad ecuatoriana. Sin embargo, hemos podido comprobar que la flexibilidad de estas redes, y su dinamismo, fueron capaces de amortiguar las que, de otro modo, hubieran sido catastróficas consecuencias. Y lo hicieron sobre la base de readaptarse a la nueva situación mediante la transnacionalización de las relaciones sociales (Gurac y Caces, 1998; Herrera, 2006). De esta forma, la red proporcionó los elementos necesarios para la reproducción social, construyendo puentes y abriendo caminos por los que circula el dinero, la información, el cuidado y todos los demás recursos necesarios para la vida. Es precisamente la capacidad de las mujeres para reconstruir y reafirmar estas redes (Camacho, 2004) y su posición en ellas lo que otorga sentido a la experiencia migratoria, y demuestra los agujeros existentes en las teorías que olvidan a los sujetos para centrarse en los hechos (Goicoechea y Ramírez, 2002; Pedone, 2005).

Son estas redes las que sostienen los proyectos de las mujeres y las que permiten su empoderamiento, limitando el impacto que el evidente y consciente descenso de clase supone para las mismas, particularmente en los primeros momentos de su experiencia migratoria. La frustración que podría derivarse de su inserción en el servicio doméstico, muchas veces en condiciones de servidumbre, es contrarrestada con una percepción fundamentalmente instrumental de su actividad. La representación social que se desarrolla no incluye al trabajo como ámbito de sociabilidad, sino como la herramienta que permite conseguir los objetivos de reproducción social. La mayoría de las migrantes opta, pues, por elaborar un discurso pragmático, dibujando una balanza donde la resignación se contrapesa con los objetivos alcanzados. Frases como: "esto es lo que hay", o "ya sabíamos a lo que veníamos" constituyen una parte de la argumentación, la otra parte la constituyen razonamientos que enfatizan la ganancia económica en términos de diferencia salarial en origen y en destino. Esta realidad parece reforzar la percepción de que en las sociedades de la globalización el trabajo pierde centralidad simbólica en la misma medida en que la gana el salario (Alonso, 2000). Sin embargo, para muchas de estas mujeres, más importante que el beneficio monetario son otras cuestiones que a veces no aparecen en este discurso, pero si en otros momentos, o que son fáciles de observar en el estudio detallado de las entrevistas. Estas cuestiones hacen referencia a los procesos de empoderamiento experimentados por muchas, aunque no todas, de las mujeres entrevistadas. Nos referimos a la autoridad alcanzada en el manejo de los mecanismos de reagrupación familiar y de la reconstitución de las redes sociales, que pueden acabar con situaciones de dependencia, abuso y subordinación en origen, o al menos minimizar su impacto. Esta autoridad, unida al prestigio que conlleva, les permite a su vez generar 
nuevas cadenas migratorias y de cuidado en origen y en destino destinadas a afianzar la nueva situación de poder de la mujer. En este sentido, es interesante destacar que la situación de "jefas de hogar" (Gregorio, 1998) las coloca en una posición de mayor agencia social y de superioridad simbólica sobre muchas de las mujeres autóctonas para las que trabajan, invirtiendo la relación de subordinación existente en el ámbito laboral.

\section{EL COLECTIVO SENEGALÉS EN SEVILLA. LA VENTA AMBULANTE}

El colectivo senegalés de Sevilla es, junto al nigeriano, el más numeroso de los colectivos procedentes del África Negra en la ciudad. Hasta la llegada de la Primera Ley de Extranjería de 1985, senegaleses y senegalesas llegaban a ferias y fiestas para vender sus mercancías y regresar después a su país. A partir de esa ley, que impedía entrar y salir libremente del territorio español, parte de estos comerciantes comenzaron a instalarse fuera, continuando con la venta e incorporando a la actividad a quienes iban llegando a través de las propias redes del colectivo. Entre estos comerciantes se encontraba ya un grupo de mujeres. Solteras, viudas, separadas o casadas pero sin sus maridos, viajan por su cuenta y se instalan en la ciudad con el propósito de mejorar su situación económica y social y las de sus familias. No será ya hasta los años noventa y primera década del presente siglo cuando el colectivo, tanto hombres como mujeres, crezca de manera importante ${ }^{4}$, haciéndose plenamente visible a través de la venta ambulante, con la instalación de puestos en distintas ferias y mercadillos, así como con la manta en las calles de centros históricos de distintas ciudades, incluida Sevilla.

Deentre las senegalesasllegadas a la ciudad por reagrupación encontramos dos situaciones: la de aquellas que permanecen la mayor parte del tiempo en la casa, contribuyendo al "equilibrio" del marido y atendiendo a quienes van llegando nuevos a la ciudad"; y la de aquellas que trabajan fuera de casa, ya sea reemplazando al marido en los negocios cuando estos salen de viaje (locutorios, puestos en mercadillos, etc.) o desarrollando una actividad independiente, lo que les posibilita una mayor autonomía. Por supuesto, la situación puede ir cambiando a lo largo del proceso migratorio. Así, de entre las mujeres que llegaron reagrupadas y han trabajado con el marido, hay quienes se han divorciado y han permanecido en Sevilla, iniciando una trayectoria autónoma.

4. La población senegalesa empadronada en Sevilla en el año 2003, según datos extraídos del Boletín Demográfico de la ciudad de Sevilla publicado en 2004, era de 228 personas. Casi las tres cuartas partes eran hombres, aunque la proporción de mujeres crece en los años posteriores. Sin duda, hemos de resaltar el evidente crecimiento de este colectivo a partir del año 2008. Según datos del Instituto de Estadísticas y Cartografía de Andalucía de la Consejería de Economía, Innovación, Ciencia y Empleo (Junta de Andalucía), la población senegalesa es para el año 2011 de 10.859 personas a nivel andaluz y de 771 para la provincia de Sevilla, la mayoría instalada en la capital.

5. Estas son una minoría y su situación responde, en numerosas ocasiones, al deseo de los hombres de tener una "mujer tradicional" tras una mala experiencia con mujeres andaluzas. 
Indudablemente, las decisiones que se van tomando en la emigración no dependen únicamente de la situación en el país receptor, también están determinadas por las expectativas y obligaciones sociales ligadas al país de origen, claramente marcadas por los roles de género. Como en toda cultura, existen en el modo de organización familiar wolof -etnia a la que pertenece la mayoría de las mujeres senegalesas de Sevilla- valores y responsabilidades asignados por sexo-género y edad, valores y responsabilidades que se están viendo modificados por las experiencias migratorias. Lo que sí se mantiene en todos los casos es el valor dado a la familia, y esto se comparte también con el resto de las senegalesas, sean de la etnia que sean. Así, la relación que se establece con los distintos miembros de la familia determina cualquier decisión. En último caso, como le vaya a cada quien en la emigración será un éxito o un fracaso a ojos de la propia familia y, a su vez, esto significará un éxito o un fracaso de la familia a ojos de la sociedad.

Como hemos señalado anteriormente, para el colectivo senegalés, en contraste con otros colectivos de inmigrantes para los que la venta constituye una primera inserción al mercado de trabajo local hasta regularizar su situación, el comercio de venta ambulante es una actividad tradicional de subsistencia que forma parte de su estilo de vida (Goldberg, 2007:283). Así, aunque mujeres de diferentes colectivos de inmigrantes encuentren en Sevilla su nicho laboral en las tareas tradicionalmente femeninas -tareas domésticas y de cuidado-, son una minoría de las mujeres senegalesas las que se dedican a estos sectores. Su principal nicho laboral es la venta ambulante que, además, les posibilita pasar largos periodos de tiempo en Senegal, viviendo a caballo entre Sevilla y Louga -o Dakar o cualquier otra de las ciudades de las que procedan- construyendo sus vidas en ambos continentes de manera simultánea (Moreno Maestro, 2006).

La venta, además, ha posibilitado el envío de remesas de una manera regular hasta hoy. Con este envío, muchas veces efectuado a través de canales informales, las mujeres contribuyen, en estos momentos con mucha más dificultad debido a la crisis económica que atraviesa España, al pago de agua, teléfono, electricidad, medicina, colegios... en origen. Y su aportación no se limita a estos aspectos, pues la participación en importantes fiestas religiosas y otras ceremonias, también depende del dinero que estas mujeres envían, ya sea para comprar un cordero, realizar una peregrinación o encargar un traje de fiesta. Es decir, no sólo la subsistencia económica, sino también la social y la cultural, viene muy determinada por las aportaciones de estas mujeres desde la emigración. Y si este éxito a ojos de la propia familia es a la vez un éxito de la familia a ojos de la sociedad, el prestigio que adquieren las mujeres que están fuera es evidente, lo que genera cambios. Así, decisiones que antes eran tomadas en la familia por hombres -principalmente por hermanos mayores-, ahora son decisiones compartidas con las mujeres que se encuentran en la emigración. 


\section{EL PAPEL DE LAS MUJERES EN LAS ASOCIACIONES DE INMIGRANTES}

\subsection{Las mujeres latinoamericanas: redes sociales y reproducción cultural}

La feminización de las migraciones en la era de la globalización es especialmente notable en los flujos procedentes de países como Ecuador, Bolivia, Colombia o Perú, especialmente durante sus primeras etapas (Herrera, 2006). No es extraño por tanto que esas mujeres pioneras ostenten una especial visibilidad en las asociaciones de estos inmigrantes. Las mujeres latinoamericanas, y muy especialmente las pertenecientes a los colectivos numéricamente mayoritarios -bolivianos, ecuatorianos, peruanos, colombianos- presentan una alta tasa de participación en el tejido asociativo de su entorno. Tanto el número de mujeres que participa de las actividades cotidianas de las asociaciones como su representación proporcional en los cargos directivos nos hablan de una importancia de la mujer que entronca, por lo demás, con la feminización observada en otras dimensiones del proceso migratorio, y que han sido expuestas en los apartados anteriores.

Es común que las asociaciones de inmigrantes constituidas por estas mujeres nazcan alrededor de una red migratoria concreta o un conjunto de ellas. La misma red que contribuye a facilitar la primera etapa de la inserción en la sociedad de destino puede optar por conformar una asociación de inmigrantes como parte de su estrategia. Esto explica que la organización de muchas de estas asociaciones descanse en la práctica sobre grupos de mujeres que con frecuencia proceden de las mismas ciudades de origen, y que a menudo sostienen entre sí vínculos de amistad o parentesco preexistentes a la propia asociación. La mayoría de las asociaciones de inmigrantes latinoamericanos identificadas en Sevilla surgieron a iniciativa de un grupo de mujeres que ya funcionaban en la práctica como grupos de apoyo mutuo antes de formalizar la asociación. En este sentido, la constitución de la asociación persigue con frecuencia la continuidad de un trabajo voluntario que es desarrollado generalmente por estos grupos.

Como consecuencia de esta tendencia, observamos que en estas asociaciones es recurrente la presencia de un grupo de voluntarias que, pese a no aparecer expresamente reconocido en los estatutos, juega un papel central en el desarrollo de las actividades cotidianas. Aunque este proceso rara vez obtenga un reconocimiento formal, la mayor parte de estas asociaciones se apoyan en grupos de mujeres que juegan un papel muy activo en el diseño y desarrollo de actividades centrales, como las celebraciones (Fiestas Patrias), talleres, exhibiciones de danzas y campeonatos deportivos. Estos grupos de mujeres voluntarias integran con frecuencia a personas de muy diferentes edades, que asumen responsabilidades específicas y cruciales para la subsistencia de la asociación. Así, por ejemplo, encontramos con frecuencia que grupos de mujeres jóvenes conforman grupos de danzas folklóricas o interpretan bailes en las celebraciones organizadas por las asociaciones. Las mujeres de mediana edad, entre treinta y cincuenta, ostentan un fuerte 
protagonismo tanto en el diseño de las actividades como en la dirección de su desarrollo. Muchas de ellas están representadas en las directivas de las asociaciones, y asumen recurrentemente la presidencia de las mismas. Finalmente las mujeres de mayor edad tienen, a diferencia de los hombres mayores, un papel muy activo en las asociaciones de latinoamericanos. Ese papel suele ser planteado como una proyección de sus labores como "abuelas-cuidadoras", y suele incluir el cuidado de los niños, cocinar en las fiestas y decorar las actividades abiertas al público. En todo caso estas redes de mujeres voluntarias prestan un trabajo crucial para el desarrollo del trabajo cotidiano de las asociaciones.

La feminización de las redes asociativas se ha traducido, en algunas asociaciones, en la activación de un criterio de género en su propia definición como organizaciones. Es el caso, por ejemplo, de la Asociación de Mujeres Inmigrantes Voluntarias y Solidarias de Andalucía (AMIVSA) o la Asociación de Mujeres de América Central. En estas asociaciones el hecho de ser mujer es un criterio esencial tanto en la definición de las socias como en la distribución de los cargos directivos. Sin embargo, la importancia de las mujeres es igualmente apreciable en asociaciones de inmigrantes que no utilizan el género como criterio asociativo. En organizaciones tan dispares como la Asociación de Amigos del Perú en Sevilla, la Casa de Chile en Sevilla o el Taller de Arte y Cultura Popular América Mestiza encontramos grupos de mujeres que juegan un papel protagonista en el desarrollo cotidiano de las actividades. Estas redes confieren a las mujeres una centralidad indiscutible en el tejido asociativo latinoamericano, que es apreciable tanto en los discursos de las propias asociaciones como en el tipo de actividades que llevan a cabo.

Los discursos de las asociaciones de inmigrantes latinoamericanos en torno a la mujer están fuertemente influidos por el protagonismo que las propias mujeres ostentan en su interior. Por tanto, reivindican la importancia de la mujer en general y de la mujer inmigrante en particular. Sin embargo, estos discursos son heterogéneos y con frecuencia heterodoxos respecto de los discursos feministas mayoritarios. Todo parece indicar que, si bien las asociaciones latinas están asumiendo con facilidad los discursos de género del entorno político, paralelamente están reforzando otros discursos sobre la mujer que las identifican en tanto que latinas. En este sentido observamos en estas asociaciones dos grandes discursos que reivindican la importancia central de la mujer. De un lado, tenemos un discurso feminista de corte occidental, que promueve una imagen moderna de la mujer latina como mujer emancipada al estilo europeo. En estos discursos se presenta a la mujer latinoamericana como una persona que obtiene sus propios ingresos mediante el trabajo asalariado, que participa de proyectos empresariales como emprendedora y que defiende su autonomía personal respecto a los modelos familiares tradicionales. Sin embargo, y de forma paralela, las asociaciones reproducen con frecuencia otro tipo de discurso sobre la mujer. En este discurso se reivindica una imagen diferenciada de 
la mujer latinoamericana, que subraya su apego a la familia y sus roles como madre y cuidadora. Este segundo discurso es con frecuencia malinterpretado desde el exterior. La población autóctona tiende a ver en esta imagen de la mujer latinoamericana un anacronismo, una especie de lastre cultural importado que dificulta la plena integración de estas mujeres. Sin embargo, es posible interpretar de otro modo el sentido de este discurso feminista no-occidental.

Una vez más, hemos de remitirnos a las redes migratorias en que participan estas mujeres. Como hemos visto, estas redes les proporcionan elementos estratégicos para la reproducción social, construyendo puentes y abriendo caminos por los que circula el dinero, la información, el cuidado y todos los demás recursos necesarios para la vida. Son estas redes las que sostienen los proyectos de las mujeres y las que permiten su empoderamiento, limitando el impacto que el evidente y consciente descenso de clase supone para las mismas, particularmente en los primeros momentos de su experiencia migratoria. Por este motivo las mujeres latinoamericanas están interesadas en reforzar discursos que, además de reivindicar su condición de mujeres, plantean modelos de feminidad diferenciados que refuerzan los vínculos con sus grupos étnicos de pertenencia. La clave está en la vinculación entre los ejes de la etnicidad y de la identidad de género. Desde esta óptica, discursos no necesariamente compartidos al cien por cien por las mujeres latinoamericanas obtienen un valor renovado por cuanto les proporcionan un discurso propio, diferenciado, como mujeres latinas. Un discurso que, curiosamente, se ve respaldado por aquellas asociaciones que demuestran un mayor conocimiento de los códigos autóctonos sobre el género. Lejos de lo que muchos pensaron, el acceso a tales códigos no les ha llevado a abandonar sus propios discursos sino a conservarlos y reforzarlos.

La convivencia de estos dos modelos de reivindicación del papel de la mujer es observable en la práctica cotidiana de las asociaciones. Muy especialmente, estos discursos se hacen patentes en dos fechas que tienen por lo general una importancia especial en el calendario de las asociaciones. Nos referimos a las celebraciones del día de la Mujer y el Día de la Madre respectivamente. Ambas fechas son festejadas por muchas asociaciones de latinoamericanos, que despliegan para estas ocasiones grandes esfuerzos en la planificación y desarrollo de los eventos conmemorativos. Tanto el Día de la Mujer como el de la Madre son celebrados de una manera similar, en forma de grandes fiestas en lugares públicos donde se convoca a socios y simpatizantes a disfrutar de actuaciones de baile, comidas y bebidas típicas. Existen en efecto rasgos que son comunes a la forma de celebrar ambas fechas. Sin embargo, los discursos y símbolos que son movilizados en una y otra difieren considerablemente.

Estas dos fiestas requieren la movilización de una máxima capacidad de trabajo por parte de los socios. Es entonces cuando se pone de manifiesto la importancia de los 
citados grupos de mujeres voluntarias. Son generalmente mujeres quienes coordinan la labor de cocina, la compra de bebidas, la planificación de las actuaciones de grupos de danzas y, en definitiva, la práctica totalidad de los preparativos previos a la celebración el evento. El mismo día de la fiesta, que generalmente se celebra en parques públicos o canchas deportivas municipales por su alta capacidad para acoger a grandes cantidades de personas, son también estas mujeres quienes dirigen las rifas y sorteos, quienes se turnan en la venta de tickets y quienes coordinan la posterior recogida y limpieza tras el evento. La celebración de estos días sirve, hacia dentro de las asociaciones, para renovar la importancia de las mujeres en la supervivencia de las mismas.

Hacia afuera, sin embargo, los discursos sobre la mujer que se reproducen en estos eventos pueden variar sensiblemente. Sería inexacto hacer una correlación directa entre los dos tipos de discursos descritos y los dos eventos reseñados, pero sí es cierto que, en general, en el Día de la Mujer predominan las referencias a los modelos feministas occidentales, mientras que en el día de la Madre se reivindica una concepción heterodoxa de la mujer latinoamericana. En el Día de la Mujer, cuya celebración es con frecuencia apoyada por instituciones públicas y/o asociaciones autóctonas, las intervenciones de las representantes de las asociaciones suelen reivindicar la importancia de las mujeres dentro de los circuitos macroeconómicos y, muy especialmente, la importancia de las mujeres inmigrantes tanto para la economía del país de origen como para la del país receptor. El Día de la Madre, sin embargo, suele ser celebrado por las asociaciones de latinoamericanos sin apoyo externo. En este caso las representantes de estas asociaciones también suelen intervenir para reivindicar la centralidad de la mujer latinoamericana. Sin embargo, en estos discursos suele enfatizarse el papel que estas mujeres cumplen dentro de sus respectivas familias, especialmente en lo tocante al cuidado del resto de miembros de las familias. La importancia de la aportación económica de estas mujeres es también remitida al ámbito familiar: se subraya el papel de la mujer como sostén de la economía doméstica y, por tanto, su buen cumplimiento del rol tradicional de reproductora del orden familiar.

La convivencia de estos dos discursos es a menudo interpretada desde el exterior como un fenómeno pasajero vinculado al proceso de modernización que se espera de estas mujeres. Muchos esperan que, con el paso del tiempo, las mujeres latinoamericanas abandonen su apego al rol materno y se adscriban definitivamente al discurso feminista occidental. Sin embargo, desde nuestra perspectiva, los modelos feministas que realzan los roles familiares de la mujer no son en este caso una reminiscencia del pasado. Por el contrario, forman parte de una estrategia compleja en la que el refuerzo de la identidad femenina es conjugado con el de unas identidades étnicas diferenciadas. Lo cual, a su vez, entronca con las características de unas redes migratorias fuertemente feminizadas. Es dentro de estas redes donde las mujeres encuentran los recursos más importantes para su 
vida cotidiana, y donde cobran sentido unos discursos que reivindican paralelamente la centralidad de las mujeres y una manera étnicamente diferenciada de construirlas.

\subsection{Asociarse entre mujeres senegalesas: el control social del ahorro}

Por su parte, un rasgo que comparte la mayoría de las mujeres africanas es su pertenencia a algún tipo de grupo o asociación. Grupos religiosos, sociedades para la mejora de la comunidad, tontines... El empeoramiento de su situación a causa de los Planes de Ajunte Estructural significó, por ejemplo, un incremento de su actividad empresarial organizada. En la actualidad, las asociaciones de mujeres constituyen el mayor sector organizado de la población en numerosos países africanos, incluido Senegal, basándose, con frecuencia, en la autoridad moral de las mujeres en tanto que madres para defender su inclusión en la política, en un modo que sería improbable fuera del continente (Bauer, 2008:105).

Sabemos que los procesos de creación, reproducción y transformación de la economía popular están ligados en Senegal a la familia, a las redes de vecindad, a la vida comunitaria. Pero, ¿qué ocurre en la emigración? ¿Existen en la sociedad receptora soportes de solidaridad, reciprocidad y ayuda mutua entre mujeres?

Sí, en este sentido podemos hablar de formas organizativas africanas que responden a estrategias comunitarias adaptadas al contexto andaluz, caso de las tontines, mayoritariamente femeninas, aunque también las hay mixtas.

La tontine de los senegaleses en Sevilla tiene lugar entre un grupo que no suele sobrepasar las 10 personas. Cada una de ellas aporta, con la periodicidad que se haya acordado normalmente, semanal o mensual- la cantidad de dinero fijada. De esta forma, se crea un fondo que se sortea según la periodicidad estipulada -cada semana o mes- y que va tocando cada vez a uno de sus miembros ${ }^{6}$. Es decir, el dinero que cada persona recauda es el mismo que aporta hasta que haya tocado a todos. ¿En qué consiste, pues, la ventaja? La tontine es una estrategia comunitaria que puede venir bien a las personas que se organizan mediante ingresos diarios, caso de las mujeres dedicadas a la venta ambulante, que podrán invertir ese dinero en alguna compra o negocio donde sea necesario el gasto de una cantidad importante de dinero de una sola vez. Se trata, en definitiva, de un sistema de ahorro. En Sevilla, cuando la situación económica era mejor a la actual, existía una tontine de mujeres con una cotización de $150 €$ semanales. En la actualidad, al haber menos ganancias, también las cotizaciones son más bajas.

Pero la función fundamental de la tontine no es solamente financiera, también cumple una importante función social (Essombe Edimo, 2002; Bagalwa Mapatano, 2004).

6. Hay tontine donde no se realiza sorteo, hay un orden prefijado de las personas que se llevarán el fondo cada semana. 
Constituye un método de pequeño crédito sin intereses. Esta estrategia económica es una forma más de afianzar la confianza mutua entre las mujeres senegalesas en Sevilla. Las reuniones de la tontine son ocasiones en las que estar juntas, son, principalmente, contextos para el encuentro.

En un sentido parecido funciona la "Asociación de Mujeres Senegalesas de Sevilla", creada en 2007. En sus estatutos se recogen como objetivos: 1) la integración laboral a través de cursos de formación (clases de español, clases de informática, de hostelería, etc.); 2) la organización de jornadas y encuentros interculturales; y 3) la implicación en el desarrollo del país de origen. Ninguna referencia, por tanto, a la actividad de la venta. El discurso de muchas de estas mujeres es que desean "trabajar" porque están cansadas de vender. Señalan que no tienen las mismas ganancias que hace años y que la presión policial es muy fuerte, por eso demandan cursos que les faciliten el acceso al empleo: cursos de carné de conducir, de español, de restauración, de hostelería, etc. Sin embargo, se trata solamente del discurso, ya que muchas de estas mujeres los rechazan cuando se les ofrece pues les impide pasar periodos prolongados de tiempo en Senegal.

La asociación cuenta con un fondo generado por cuotas, $10 €$ al mes. Parte de este fondo está pensado para emplearse en un sistema de préstamo, permitiéndose, además, que quienes regresen definitivamente a Senegal puedan continuar en la asociación y, por tanto, seguir beneficiándose del sistema de préstamo.

De esta forma, con esta organización se asegura un control social del ahorro y se contribuye al afianzamiento de las redes de género dentro del colectivo senegalés de la ciudad. En este sentido, el papel de las reuniones es fundamental. En ellas no sólo se tratan cuestiones relacionadas directamente con la asociación, también es muy común que se vendan artículos unas a otras: pañuelos llegados de la Meca, artículos de higiene de Senegal... Incluso mujeres que no trabajan fuera de casa y ocupan casi todo su tiempo en atender a sus maridos y demás miembros de la familia asisten a estas reuniones, donde lo fundamental es el encuentro. Prestar, pedir prestado, dar, recibir, ayudarse, informarse, organizar eventos, etc. Todo toma un tiempo considerable y ocupa una parte importante de la jornada.

Podemos afirmar, entonces, que la mayor parte de las mujeres senegalesas entiende que subsistir depende, en gran medida, de la solidaridad no solo étnico-nacional, sino también de género, solidaridad que intensifica, y más en estos momentos, el sentimiento de pertenencia al grupo.

7. La venta ambulante no la consideran trabajo. Es muy frecuente escuchar entre las personas que se dedican a la venta ambulante: "yo no trabajo, yo vendo". 


\section{GÉNERO Y GENERACIÓN}

En las investigaciones sobre mujeres migrantes no se ha explicitado suficientemente el rol que los menores juegan, por activa y por pasiva, en la construcción de las redes migratorias transnacionales y en las dinámicas (culturales, simbólicas, sociales y económicas) que albergan en ellas. Esta invisibilidad queda más explícita en los análisis sobre flujos migratorios feminizados, como por ejemplo los que involucran América Latina y España en la contemporaneidad. Muchas mujeres migrantes latinoamericanas que componen este flujo son madres que configuran la red familiar transnacional alrededor del cuidado de los hijos que se han quedado en el lugar de origen (Martín Díaz y alii, 2007; Pedone, 2008; Lagomarsino, 2006). Es decir, el denso entramado material y simbólico de los flujos financieros (remesas) y no financieros (intercambio de favores, regalos, llamadas, viajes...) que configuran el llamado "cuidado transnacional" (Boccagni, 2012) es uno de los pilares sobre los que se crean y se sustentan estas redes.

En los estudios que hemos llevado a cabo en Sevilla sobre menores migrantes, hemos puesto de manifiesto cómo estos chicos están sometidos a un proceso de invisibilización y inferiorización por su doble condición de menores de edad y migrantes que operan a diferentes niveles de análisis (Martín Díaz et al., 2012). A nivel familiar, hemos señalado cómo en las familias migrante los menores, por un lado, resultan centrales en la justificación y en la puesta en marcha del proyecto migratorio, dado que a menudo los adultos justifican el hecho de migrar para garantizar un porvenir más fructífero a los descendientes, tanto en origen como en destino: mejor educación, calidad de vida, y otros argumentos centrados en el bienestar de los hijos. Por otro lado, sin embargo, la mayoría de los adultos cuidadores excluyen a los menores de las decisiones que resultan cruciales para su futuro: apenas son consultados en la decisión de migrar de los padres, ni tampoco cuando los adultos deciden reagruparlos en el lugar de destino o deciden retornar al lugar de origen.

Si observamos como son considerados estos menores, al nivel del Estado-Nación podemos afirmar que en el país de destino, los hijos, tanto los reagrupados como los nacidos en el país, aparecen en los discursos políticos, mediáticos y también académicos, sólo en cuanto problema cultural y social para la cohesión de la sociedad (Queirolo, 2012 [en este número]). A la problematización en destino, corresponde aquella imagen especular construida por el Estado-Nación de origen. Los hijos de los emigrantes que se quedan en el lugar de origen, en particular en aquellos modelos migratorios en los que las que migran primeras son las mujeres (p.e. el flujo ecuatoriano a España), son definidos por la opinión pública como "desviados potenciales", por no haber tenido una "educación familiar normal" dado que sus madres los han "abandonado" abdicando de su obligación "natural" de cuidadora ${ }^{8}$.

8. Para el caso de Ecuador véase, entre otros, Herrera y Martínez (2003). 
En el lugar de destino, estos menores se asoman a la ventana de la Historia solo cuando empiezan a representarse en el imaginario de la sociedad receptora como un peligro potencial por la homogeneidad de la Comunidad Nacional (p.ej. se habla de aulas "repletas de alumnos extranjeros" y de la necesidad de "medidas de integración") o como un problema de orden público. Merece la pena subrayar en este sentido que en la historia de las ciencias sociales los hijos de inmigrantes empiezan a visibilizarse, propiamente, como miembros de gangs (bandas) en trabajos etnográficos fundacionales como el que White (1943) llevó a cabo en un gueto de inmigrantes italianos en Boston. También en la actualidad se siguen financiando por las distintas administraciones del Estado muchos estudios para investigar el tema de las pandillas juveniles compuestas por hijos de migrantes (Queirolo Palmas y Torre, 2005; Cerbino, 2006; Feixa, Porzio y Recio, 2006) dado que se considera a estas pandillas como la manifestación en carne y hueso de la amenaza implícita en la naturaleza del Otro inmigrante, que se ha transferido sobre sus descendientes biológicos (García Borrego, 2003). Por otra parte, estos trabajos han puesto de manifiesto, que la problematicidad de los hijos de migrantes está claramente generizada, dado que la mayoría de los componentes de las pandillas son jóvenes varones. A las chicas hijas de inmigrantes tampoco se las visibiliza como problemáticas y, por tanto, desparecen completamente de la esfera pública.

En los trabajos de investigación en que hemos analizado la construcción de identidades y la inserción sociocultural de los hijos de inmigrantes latinoamericanos en Sevilla (la mayoría reagrupados) destacamos cómo las chicas juegan un papel central en el proyecto migratorio familiar ya a partir del lugar de origen (Martín Díaz et al., 2012; Lagomarsino y Castellani, 2011). Allí, las chicas que están en edad preadolescente en el momento de la partida de las madres, aunque estén al cuidado de otros adultos, participan casi siempre en la redistribución de la carga de labores de cuidado y de trabajo domestico en la casa, lo que no sucede con los varones coetáneos de la familia, asumiendo sobre sus espaldas gran parte de aquel "sacrificio" que hizo la madre al tener que abandonar su hogar para migrar a otro país (Herrera y Carrillo, 2009). Algunas investigaciones, además, han señalado cómo las chicas que permanecen en el lugar de origen, a pesar de su minoría de edad, juegan también un papel destacado en la gestión de las remesas (Castillo, Patiño y Pesántez, 2003).

Si nos centramos en la familia en el lugar de destino, son otra vez las chicas las que se encargan de la mayoría del trabajo doméstico y de cuidado de hermanos menores, sustituyendo a las adultas cuidadoras que están empleadas en el trabajo extradoméstico. Además, estas adolescentes, cuando están libres de obligaciones escolares, durante los fines de semana o el verano, también ayudan a otras mujeres adultas de la familia, la mayoría empleadas en trabajos domésticos y de cuidado, o desarrollan actividades parecidas en el mismo nicho laboral: canguro, acompañar a personas mayores dependientes de veraneo, etcétera. 
A pesar de tener esta sobrecarga de trabajos respeto a los varones coetáneos de la familia, obtienen mejores resultados escolares que ellos. En algunas investigaciones que se centraron en las hijas de inmigrantes se observó que la escuela juega un papel fundamental en las vidas de estas chicas: por un lado el éxito escolar reproduce el modelo tradicional femenino de la "buena chica" y, por el otro, un mejor nivel de educación parece ser una ventaja competitiva en el mercado del trabajo para las chicas, mucho más que para los chicos (Ravecca, 2010). En nuestras investigaciones llevadas a cabo en Sevilla observamos que muchas chicas latinoamericanas consideran el éxito escolar como una forma de promoción de estatus en un sistema social donde los padres padecen una movilidad descendente. Además, el éxito escolar representa un emblema de distinción en aquellas zonas residenciales "periféricas", donde se concentra la mayoría de migrantes latinoamericanos, en las cuales el fracaso escolar es considerado la normalidad. Por tanto, el éxito en la escuela parece ser, por un lado, una visibilización y, por el otro, una especie de "redención" para las chicas, y una oportunidad de salir de la triple inferiorización como mujeres, hijas de migrantes y menores. Una "redención" que se puede comparar con la emancipación del sistema patriarcal que experimentaron muchas de sus madres en las redes migratorias de mujeres (Lagomarsino y Castellani, 2011).

Hay que apuntar, de todas formas, que el trabajo que las chicas desarrollan en la casa representa también una forma de control indirecto. Las chicas son más vigiladas que los chicos, como toda mujer adolescente en la mayoría de las sociedades. El cuerpo de las adolescentes, de hecho, es controlado continuamente porque su sexualidad no es encauzada hacia el matrimonio (entendido como institución social) y un potencial embarazo puede engendrar problemas para la reproducción del estatus de la familia dentro del grupo social de referencia (Schlegel, 1995). Sin embargo, hay que considerar también que sobre el cuerpo de las mujeres adolescentes hijas de inmigrantes, como afirma Le Espiritu, (2003), se tiende a construir el limite étnico con respecto al grupo étnico mayoritario. En la intención de los padres las chicas tienen que ser educadas como "buena ecuatoriana" o "buena latinoamericana" (no estar en la calle mucho tiempo y sobre todo con hombres, ayudar en la casa, salir por la noche acompañada, etcétera) ${ }^{10}$. Por tanto, a través de la educación de las chicas se reproduce tanto el modelo tradicional de los roles de género como los limites étnicos de la minoría.

Nos encontramos frente a la que Bourdieu (2000) llamaba la paradoja de la doxa. Por

9. En Sevilla y en Andalucía no tenemos estadísticas o investigaciones cuantitativas que respalden nuestros datos etnográficos. Sin embargo la tendencia parece confirmar lo que ha sido señalado por otros trabajos en España (Colectivo IOE, 2003) y en otros países como Italia (Ravecca, 2009; Besozzi, Colombo y Santagati, 2009).

10. Este modelo de educación está "re-inventado" en destino y se corresponde sólo en parte con los patrones que se utilizan en el país de origen (que varían entre ellos de forma notable dependiendo, sobre todo, de la pertenencia de clase). 
un lado, estas chicas se crían en una red transnacional de mujeres en la cual, como se decía anteriormente, se ha empezado a poner en tela de juicio el sistema patriarcal. Por otro lado, son estas mismas mujeres y madres las que reproducen este mismo modelo patriarcal al que han desafiado en el criado de sus hijas (Lagomarsino y Castellani, 2011). Por tanto, en la vida cotidiana de estas chicas se observa un balanceo continuo entre una aceptación pasiva de los roles de género y de la pertenencia a una familia de la minoría y un rol activo de cuestionamiento de estos modelos de pertenencia de género y étnica. Estas condiciones está constantemente negociadas por estas chicas, manejando los códigos culturales familiares y juveniles. Por ejemplo, la cuestión de la substracción del tiempo libre para dedicarse a las tareas de cuidado es considerada por un lado, como un deber "normal" por estas chicas, sin embargo, al mismo tiempo, es también cuestionado, aferrándose a los patrones de tiempo libre de las coetáneas hijas de "autóctonos" (Ibid., 2011).

En esta línea, también, habría que considerar el tema de los llamados embarazos precoces de las chicas latinoamericanas. En primer lugar, hay que subrayar que este tema es uno de los pocos en los cuales se visibilizan públicamente las hijas de los inmigrantes. Al igual que las pandillas de varones, el embarazo adolescente de estas chicas es representado como un problema por los agentes sociales y la opinión pública. Desde el sentido común de la sociedad de destino, se esgrime una lectura culturalista de estos embarazos presentándolos como ejemplos de la reproducción de un modelo patriarcal de la "subdesarrollada" sociedad de origen en la que la mujer está todavía circunscrita a su rol de madre y esposa. Para deconstruir este punto de vista, hemos considerado oportuno recuperar los trabajos llevados a cabo por la Escuela de Birmingham sobre los adolescentes de la clase obrera del Reino Unido de los años 80, que mostraron cómo los embarazos adolescentes en la época del mandato de M. Thatcher eran una estrategia de estas mujeres "autóctonas" excluidas del mercado de trabajo postfordista. Desde el punto de vista simbólico, era una vía para conquistar un rol social visible y definido y, desde el punto de vista material, les permite acceder a los susidios estatales de maternidad y poder así garantizarse un salario de subsistencia (McRobbie, 2000).

En segundo lugar, para entender estos embarazos, hay que tener en cuenta que en muchas de las familias transnacionales donde se han criado estas chicas, hay experiencias de una o más mujeres "madres solteras", que han tenido hijos en edad temprana y han sido abandonadas por sus parejas. La mayoría de las chicas adolescentes que se quedan embarazadas son, de la misma manera, abandonadas por el padre natural del hijo/a, sin embargo, el aborto no es contemplado como solución prioritaria. Eso tiene que ver sólo en menor medida con una ideología "antiabortista", que se atribuye a la fuerza de la religión cristiana en la "cultura de origen", sino que se relaciona mayoritariamente con la posibilidad de contar con un apoyo para el cuidado en las redes transnacionales de mujeres en las que están insertadas estas chicas. 
Así que el cuadro resulta más complejo de como se suele dibujar. Por un lado, en la decisión de ser madre, juega un factor de visibilidad y reconocimiento social que se consigue con la maternidad. Por el otro, esta condición es considerada como algo "normal" dado que en el entorno familiar se acepta la maternidad "temprana" como una opción compatible y viable. Aunque a menudo el embarazo no es una elección racionalmente programada, parece ser, sin embargo, una opción aceptada conscientemente por estas chicas. Esto va en contra de lo que se presume desde la sociedad de destino, o sea que por ser menores de 18 años y no tener pareja estable no pueden asumir conscientemente el cuidado de un hijo y que lo que están haciendo es seguir los "retrasados" patrones de la cultura de origen sin cuestionarlos. La capacidad de agencia de estas chicas, por tanto, las configura como sujetos sociales que se socializan y operan dentro de la estructura social, pero que no se limitan a reproducirla pasivamente, sino que tienen márgenes para modificarla a partir de su exclusión como mujeres, menores e hijas de inmigrantes (Lagomarsino y Castellani, 2011).

Concluyendo, en los estudios de los proyectos migratorios se percibe la necesidad de incorporar en el marco del análisis la relación entre género y generación, intentando visibilizar el papel fundamental que las chicas juegan en el proyecto migratorio, en la reproducción familiar y en sus propias vidas en el lugar de destino. En la actual crisis de empleo que está golpeando tenazmente a muchas familias inmigrantes en Andalucía, son las mujeres inmigrantes, otra vez, quienes reconquistan el papel central de sustentadoras de sus hogares, dado que la mayoría de los hombres se han quedado sin empleo con el derrumbe que conoció el sector de la construcción cuando se desinfló la burbuja inmobiliaria. De la misma forma, considerando que el nicho feminizado del mercado de trabajo en que están insertadas estas mujeres ofrece todavía oportunidad de empleo aun en esta época de crisis, las familias "invierten" propiamente sobre las chicas para seguir sacando adelante el proyecto migratorio en destino. Esto influye también en las decisiones sobre el retorno al país de origen. Por ejemplo, entre los inmigrantes latinoamericanos en Sevilla se está afianzando una estrategia de retorno focalizada, que no pone fin al proyecto migratorio, sino que reestructura la configuración y la movilidad intra-familiar, privilegiando la permanencia de las mujeres respeto a los hombres. Esto vale también para las menores de las familias. Mientras que sus coetáneos varones, al igual que los hombres adultos, no tienen un porvenir de inserción en un mercado de trabajo postrado por la crisis, las chicas tienen abierta la posibilidad de emplearse en el mismo nicho laboral que las madres, aunque la familias sigan invirtiendo en sus estudios como una estrategia destinada a lograr que ellas puedan tener una movilidad ascendente y elevar, de esta forma, el estatus familiar. 


\section{CONCLUSIONES}

Hemos podido comprobar cómo a lo largo del proceso migratorio las mujeres van redefiniendo sus estrategias, sin que ello implique en ningún caso la ruptura con la sociedad de origen. Sin embargo, sí es cierto que la vinculación no sólo económica y social, sino también simbólica y cultural va experimentando una serie de transformaciones en relación a la evolución del proceso.

Las redes sociales tejidas en las primeras fases de la migración tienen como unidad de referencia el grupo doméstico. Es en base a las necesidades del grupo que se va definiendo el ritmo del proyecto migratorio. Entre estas necesidades suelen destacar el acceso a la vivienda y el empleo, así como la regularización de la situación administrativa del migrante. Sin embargo, el transcurso del tiempo hace que aparezcan nuevas necesidades ligadas a la perspectiva de permanecer en Sevilla. Con la reagrupación familiar y la formación de nuevas unidades domésticas, se va generalizando entre los migrantes la preocupación por conservar su identidad cultural en tanto miembros de una sociedad donde son minoría. No es extraño por tanto que aparezcan en estos momentos redes sociales que asumen ya como objetivo expreso la defensa y potenciación de la identidad cultural del grupo.

A diferencia de las centradas en el grupo doméstico, estas redes tienen como objetivo la representación de todo un grupo étnico o incluso un conjunto de ellos. Esto no significa que todo el grupo étnico participe por igual de estas redes, ni que los grupos domésticos pierdan necesariamente su centralidad en buena parte de las funciones asignadas a la red. Lo importante en este punto es que la referencia simbólica que legitima la existencia de la red es el grupo étnico en tanto minoría cultural. Este cambio entraña a su vez otras novedades significativas, principalmente en los objetivos que guían el funcionamiento de la red, las prácticas y discursos que se implementan para alcanzarlos y los escenarios en los que se despliegan las estrategias básicas.

Este nuevo tipo de red social, orientado a la reproducción colectiva en términos de minoría étnica, es la base material para el despliegue de lo que se suele considerar como estrategias asociativas migrantes propiamente dichas. La reivindicación de una identidad étnica compartida y de la representatividad sobre ésta conlleva la idea implícita de una sociedad autóctona como contraparte interlocutora. Esta dualidad exige a su vez que los líderes que ocupan los nodos centrales de estas redes no sólo cumplan con la función de representar a la comunidad, sino también con la de tener acceso a las instituciones centrales de la sociedad de inserción y relacionarse eficazmente con ellas (Rex, 1994). Si la red social es la base de las estrategias asociativas, estas estrategias no tienen por qué materializarse siempre de las mismas formas. De hecho, las formas concretas de asociación pueden variar sustancialmente en función del marco legal existente, la cultura política de los migrantes, los marcadores identitarios de referencia (Barth, 1976) y otras variables, como hemos podido comprobar. 
El interés de las mujeres por conservar su propia identidad se traduce paralelamente en prácticas que persiguenla reproducción de su existencia en tanto comunidad transnacional. Las ecuatorianas y sengalesas residentes en Sevilla despliegan cotidianamente estrategias de vinculación con su país de origen. Y en este caso también es apreciable la importancia que la identidad de género juega en la construcción de esos vínculos. Podría decirse que, a la hora de participar, las mujeres migrantes pugnan por mantener a salvo la autonomía alcanzada a través de su control sobre las redes migratorias. 


\section{REFERENCIAS BIBLIOGRÁFICAS}

Actis, Walter (2005) "Ecuatorianos y ecuatorianas en España. Inserción (es) en un mercado de trabajo fuertemente precarizado". En: Herrera, Carrillo y Torres (eds.) La migración ecuatoriana. Transnacionalismo, redes e identidades. Quito: FLACSO, pp.169202.

Alonso, Luis E. (2000) Trabajo y posmodernidad. El empleo débil. Madrid: Fundamentos. Barth, Fredrik (1976) Los grupos étnicos y sus fronteras: la organización social de las diferencias culturales. México: Fondo de Cultura Económica.

Basch, Linda; Schiller, Nina Glick y Szanton Blanc, Cristina (1994) Nations unbound: transnational projects, postcolonial predicaments, and deterritorialized nation-states, London: Gordon and Breach.

Bauer, Gretchen (2008) "Mujeres y activismo político en el África del siglo XXI". África. Vanguardia Dossier, № 26, pp. 102-105.

Besozzi, Elena; Colombo, Maddalena y Santagati, Mariagrazia (2009) Giovani stranieri, nuovi cittadini. le strategie di una generazione ponte. Milano: Franco Angeli.

Boccagni, Paolo (2012) "Practising Motherhood at a Distance: Retention and Loss in Ecuadorian Transnational Families". Journal of Ethnic and Migration Studies, vol. 38, N 2.

Bourdieu, Pierre (2000) La dominación masculina. Barcelona: Anagrama.

Camacho, Gloria (2004) "Feminización de las migraciones en Ecuador". En Francisco Hidalgo (comp.) Migraciones. Un juego con cartas marcadas. Quito: Ed. Abya Yala, 303326.

Castillo, Rául; Patiño, Marisol y Pesántez, Blanca (2003) Incidencia de la emigración en la construcción de la identidad y proyecto de vida de los jóvenes, Giron, 2002. Informe de investigación. Cuenca (Ecuador): Universidad de Cuenca.

Cerbino, Mauro (2006) Jóvenes en la calle: cultura y conflicto. Barcelona: Anthropos.

Colectivo IOE (2003) La escolarización de hijas de familias inmigrantes. Un análisis de la distribución por sexos del alumnado de origen extranjero en España. Madrid: CIDE.

Cuberos, Francisco José (2008) "El movimiento como mecanismo de renegociación de la identidad: el caso de las mujeres ecuatorianas en Sevilla". En: Gioconda Herrera y Jacques Ramírez (eds.) América Latina migrante: Estado, familia, identidades. Quito: FLACSOEcuador. 
Essombe Edimo, Jean Roger (2002) "La naturaleza profunda de la tontina africana". En: A la búsqueda de alternativas, ¿otro mundo es posible?, Alternativas Sur, vol. I. Bélgica: Centre Tricontinental, Louvain-La-Neuve, pp. 143-152.

Feixa, Carles, Porzio, Laura y Recio, Carolina (2006) Jóvenes latinos en Barcelona. Espacio público y cultura urbana. Barcelona: Anthropos.

Floro, Maria (2001) "Gender Dimensions of Financing Development Agenda", documento de trabajo encargado por UNIFEM.

García Borrego, Iñaki (2003) "Los hijos de inmigrantes como tema sociológico: la cuestión de la segunda generación". Anduli: revista andaluza de ciencias sociales, $\mathrm{N}^{\circ} 3$.

Goldberg, Alejandro (2007) "Dinámicas y estrategias socioculturales de inserción económica de los migrantes senegaleses: una indagación etnográfica”. En: Empresariado étnico en España. Barcelona: Fundación CIDOB, pp. 113-139.

Goycoechea, Alba y Ramíre, Franklin (2002) "Se fue, ¿a volver? Imaginarios, familia y redes sociales en la migración ecuatoriana a España (1997-2000)”. Revista Iconos. 14, pp. $32-45$.

Gregorio, Carmen (1998) Migración femenina. Su impacto en las relaciones de género. Madrid: Nancea.

Gurak, Douglas y Caces, Fe (1998) "Redes migratorias y la formación de sistemas de migración". En: Graciela Malgesini (comp.) Cruzando fronteras. Migraciones en el sistema mundial. Madrid: FUHEM-Icaria, pp. 75-110.

Herrera, Gioconda y Martínez, Alexandra (2003) Género y migración en la región Sur. Informe de investigación. Quito: Flacso-Ecuador.

Herrera, Gioconda (2003) "La migración vista desde el lugar de origen". Revista Iconos, 15, pp. 86-94.

Herrera, Gioconda (2004) "Elementos para una comprensión de las familias transnacionales". En: Francisco Hidalgo (coord.) Migraciones. Un juego con cartas marcadas. Quito: Abya Yala.

Herrera, Gioconda (2005) "Mujeres ecuatorianas en las cadenas globales de cuidado". En: Herrera, Carrillo y Torres (eds.) La migración ecuatoriana. Transnacionalismo, redes e identidades. Quito: FLACSO, pp. 281-304. 
Herrera, Gioconda (2006) "Precarización del trabajo, crisis de reproducción social y migración en España: ecuatorianas en España y Estados Unidos”. En Herrera (Ed.) La persistencia de la desigualdad. Género, trabajo y pobreza en América Latina. Quito: FLACSO, CONAMU, Secretaría Técnica del Frente Social, UNFPA.

Herrera, Gioconda y Carrillo, María Cristina (2009) "Transformaciones familiares en la experiencia migratoria ecuatoriana. Una mirada desde los contextos de salida”. Revue des Mélanges de la Casa Velasquez, vol. 39, № 1 .

Lagomarsino, Francesca (2006) Esodi ed approdi di genere. Famiglie transnazionali e nuove migrazioni dallecuador. Milano: Franco Angeli.

Lagomarsino, Francesca y Simone Castellani (2011) "The invisible protagonists. An analysis on the role of Ecuadorians' daughters in Southern Europe and in the origin localities" en The Migration-Development Nexus Revisited: State of the Art and Ways Ahead, University of Trento, junio 8-10, en linea http://www.tcic.eu/c/document library/ get file?uuid=60fc60c8-6e32-4688-9c87-4d9098ac473f\&groupId=12226

Le Espiritu, Yen (2003) "We Don't Sleep Around Like White Girls Do. Family, Culture, and Gender in Filipina American Lives". En: Pierrette Hondagneu-Sotelo (ed.) Gender and U.S. Immigration: Contemporary Trends. Ewing (NJ): University of California Press, pp. 263-283.

Martín Díaz, Emma (2006) "De las migraciones del fordismo a las migraciones de la globalización. Europa: 1960-2005”. África e Mediterráneo, 54: 29-35.

Martín Díaz, Emma y Sabuco, Assumpta (2006) "Las mujeres en la globalización: el nuevo tráfico entre alianzas y mercancías". RELEA, Revista Latinoamericana de Estudios Avanzados, 24: 65-106.

Martín Díaz, Emma y alii (2007) El papel de las mujeres inmigrantes en el desarrollo de sus localidades de origen: el caso de las marroquíes y las ecuatorianas. Madrid: Instituto de la Mujer. Secretaría General de Políticas de Igualdad.

Martín Díaz, Emma (2008) “El impacto del género en las migraciones de la globalización: mujeres, trabajo y relaciones interculturales". Scripta Nova Revista Electrónica de Geografía y Ciencias Sociales, vol. XII núm. 270 (133)http://www.ub.es/geocrit/sn/sn-270/sn-270$\underline{133 . h t m}$

Martín Díaz, Emma et alii (2008) El papel de las mujeres inmigrantes en el desarrollo de sus localidades de origen: el caso de las marroquies y las ecuatorianas. Madrid: Ministerio de Igualdad. 
Martín Díaz, Emma; Benítez, Jorge; Castellani, Simone y Cuberos, Francisco (2012) Vidas de ida y vueltas. Inmigrantes latinoamericanos en Sevilla. Sevilla: Universidad de Sevillla.

Moreno Maestro, Susana (2006): Aquí y Allí, viviendo en los dos lados. Los senegaleses de Sevilla, una comunidad trasnacional. Sevilla: Dirección General de Coordinación de Políticas Migratorias, Consejería de Gobernación, Junta de Andalucía.

McRobbie, Angela (2000) Feminism and youth culture. London: Mc Millan Press.

Parpart, Jane (1988): "Women and the State in Africa". En: Donald Rothchild y Naomi Chazan (eds.) The Precarious Balance: State and Society in Africa, Westview Press.

Pedone, Claudia (2005) Inmigración y familias de Ecuador a Cataluña. Trayectorias socioespaciales. Barcelona: Fundació Jaume Bofill.

Pedone, Claudia (2005) Inmigración y familias de Ecuador a Cataluña. Trayectorias socioespaciales. Barcelona: Fundació Jaume Bofill.

Pedone, Claudia (2008) “'Varones aventureros'vs. 'Madres queabandonan': reconstrucción de las relaciones familiares a partir de la migración ecuatoriana”. Revista Interdisciplinar da Mobilidade Humana, Año XVI, 30: 45-64.

Pedone, Claudia (2008) Estrategia migratorias y poder. Tu siempre jalas a los tuyos. Quito: Abya-Yala. Queirolo Palmas.

Queirolo, Luca y Torre, Andrea (2005) Il fantasma delle bande. Genova e i latinos. Genova: Frilli.

Ramírez, Franklin y Ramírez, Jaime (2005) La estampida migratoria ecuatoriana. Crisis, redes transnacionales y repertorios de acción migratoria. Quito: Abya-Yala, Centro de investigaciones Ciudad, ALISEI, UNESCO.

Ravecca, Andrea (2009) Studiare nonostante. capitale sociale e successo scolastico degli studenti di origine immigrata nella scuola superiore. Milano: Franco Angeli.

Ravecca, Andrea (2010) "Immigrant children school experience: how gender influences social capital formation and fruition?" Italian Journal of Sociology of Education, vol. 4, $\mathrm{N}^{\circ} 1$.

Rex, John (1994) "Ethnic mobilisation in multi-cultural society". En G. Pohoryles, J. Rex, H. Kreutz and P. Schlesinger (eds) European Transformation: Five Decisive Years at the Turn of the Century. Avebury: Aldershot, pp. 214-226. 
Sassen, Saskia (1998) Globalization and its discontents. Essay on the new mobility of people and money. New York, The New Press.

Sassen, Saskia (2003) Contrageografías de la globalización. Género y ciudadanía en los circuitos transfronterizos. Madrid: Traficantes de Sueños.

Schlegel, Alicia (1995) “The cultural management of adolescence sexuality”. En: Paul R. Abramson (ed.) Sexual Nature, Sexual Culture. Chicago: The University of Chicago Press. 